\title{
Proximal Femoral Focal Deficiency (PFFD): a Report of Two Rare Cases in Cameroon
}

\author{
Nana Chunteng Theophile ${ }^{1 *}$, Ngo-Yamben Marie Ange ${ }^{2}$, Fokam Pius ${ }^{1}$, Naiza Monono ${ }^{3}$, Nkoke Clovis ${ }^{3}$, Fon Phyllis ${ }^{3}$, \\ Bombah F Mertens ${ }^{2}$ and Palle J Ngunde ${ }^{1}$ \\ ${ }^{1}$ Department of Surgery, Faculty of Health Sciences, University of Buea, Cameroon \\ ${ }^{2}$ Department of Surgery and specialties, Faculty of Medicine and Biomedical Sciences, University of Yaounde 1, Cameroon \\ ${ }^{3}$ Department of Internal Medicine and Pediatrics, Faculty of Health Sciences, University of Buea, Cameroon
}

Submission: September 17, 2021; Published: September 28, 2021

*Corresponding author: Nana Chunteng Theophile, Department of Surgery and Specialties, Faculty of Health Sciences, University of Buea, Cameroon

\section{Abstract}

Proximal femoral focal deficiency (PFFD) is a rare and sporadic congenital anomaly. The femoral dysplasia may range from hypoplastic femur to the severe form of femoral agenesis. Only few cases have been reported in Africa, and none in Cameroon before now. We hereby report two cases of PFFD, among which one is an unusual case of femoral agenesis. The were no identifiable risk factors for this anomaly in the maternal and family histories. Definitive treatment of this anomaly is complex, challenging, multidisciplinary, and somewhat difficult to carryout in limited resource facilities.

\section{Introduction}

Congenital limb defects represent generalized disorders of cartilage and bone [1]. They are made up of more than 200 heterogeneous disorders, characterized by abnormalities of cartilage and bone growth - resulting in abnormal shape and size of the skeleton and disproportion of the bones [2]. Congenital limb defects are obviously recognized at birth and can cause various effects on appearance and psychology which can lead to long lasting adverse outcomes for health and social integration [3]. Proximal femoral focal deficiency (PFFD), also known as congenital proximal femoral deficiency (CPFD) is a congenital limb defect which is a subset of a broader group called congenital femoral deficiency. It is a rare congenital anomaly with an incidence of 1.1-2.0 in100,000 live births [4]. The dysplasia in PFFD may range from hypoplastic shortened femur to total absence of proximal two-thirds of the femur, or the severe form of femoral agenesis [5]. PFFD is not a chromosomal abnormality and may be associated with other congenital abnormalities or syndromes like fibula hemimelia, femoro-fibula-ulna syndrome, coxa vara, oligodactyly and patella agenesis [4].

Risk factors for PFFD include maternal hypoxia, ischemia, diabetes mellitus, irradiation, microbiological agents, chemical toxicities, hormones, mechanical injuries, thermal injuries, thalidomide exposure, and trauma to the fetus and/or mother between the fourth and eighth weeks of gestation [6]. Although PFFD is an uncommon, unusual and sporadic anomaly, some cases have been reported in some African countries including Nigeria [7,8], Rwanda [9] and Egypt [10], and none in Cameroon before now. We hereby report two rare cases of PFFD, seen within a period of 3 months, among which one is an unusual case of femoral agenesis. These rare cases deserve to be added to the few existing literatures of PFFD.

\section{Case Presentation}

\section{Case 1: left femoral agenesis}

This a 2-month-old male baby was born at 38 weeks gestation through a normal per-vaginal route of delivery with cephalic presentation. The mother is 28 years old, and he didn't report any abnormalities during pregnancy. The baby presented with a history of shortened left lower limb that was noticed at birth. He weighed 3200g and had an APGAR score of 9 at 1 minute and 9 at 5 minutes. The mother didn't report exposure to radiations, nor gestational diabetes. She adequately took folic acid and didn't take non-prescribed drugs during the pregnancy. She had no history of trauma during the pregnancy. She did ultrasound scans during pregnancy which did not show fetal abnormalities. There was no family history of similar occurrences. His older sibling 


\section{Orthopedics and Rheumatology Open Access Journal (OROAJ)}

doesn't have any skeletal anomalies. On physical exam, his left thigh was thick, short and bulkier than the right, with an absent hip (Figure 1A). His right lower limb and both upper limbs were normal. His facial appearance was normal. The x-rays of the lower limbs showed absent left femur, a dysplastic acetabulum and an overriding tibia and fibula (Figure 1B). These findings were consistent with a femoral agenesis.

Figure 1A: Clinical picture of index case 1, a 2-month-old male baby with a thick left thigh that is short and bulkier than the right. The hip is absent.
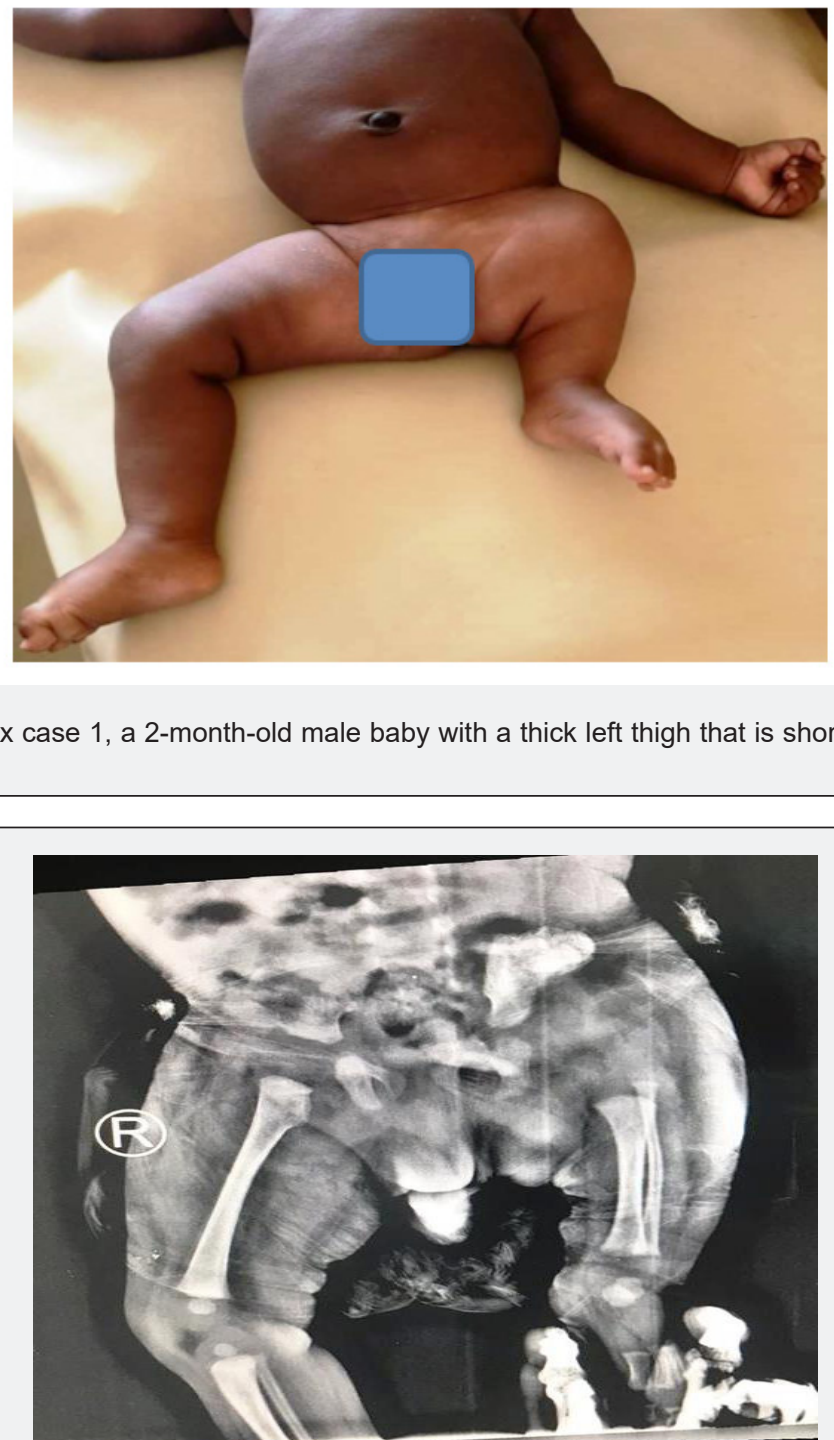

Figure 1B: X-rays of index patient 1 showing absence of the left femur, a dysplastic left acetabulum and an overriding left tibia and fibula. This image is consistent with a femoral agenesis.

\section{Case 2: left PFFD}

The orthopedic team was called upon to examine a 1-dayold male baby, lone child born to a 28 -year-old lady. He had a short thigh that was noticed during cesarean delivery indicated for complete breech presentation and stationary labour. The male newborn weighed 3100g and had an APGAR score of 8 at 1 minute and 10 at 5 minutes and had normal facial features. His parents are non-consanguinous. There was no antenatal history of maternal diabetes, non-prescribed drug intake, or perinatal exposure to radiation. There was no history of trauma to or fall of his mother during the antenatal period. There was no positive family history of previous similar occurrence. On physical examination, his left thigh was bulkier than the right. It was flexed, laterally rotated, and the hip joint was abducted (Figure 2A). The range of movements at her left hip was limited to a fixed flexion deformity. The range of motion of the left knee was limited to less than $45^{\circ}$ flexion. His left ankle showed limitation of ankle dorsiflexion. Both upper limbs showed no anomaly. He had normal head size with normal facial features. The right hip and upper limbs were normal. Radiographic evaluation revealed 


\section{Orthopedics and Rheumatology Open Access Journal (OROAJ)}

a shortened left femur with absence of the femoral head. The acetabulum looked normal. There was some degree of Coxa vara and the distal femoral condyles were hypoplastic (Figure 2B). these findings were consistent with a left PFFD.

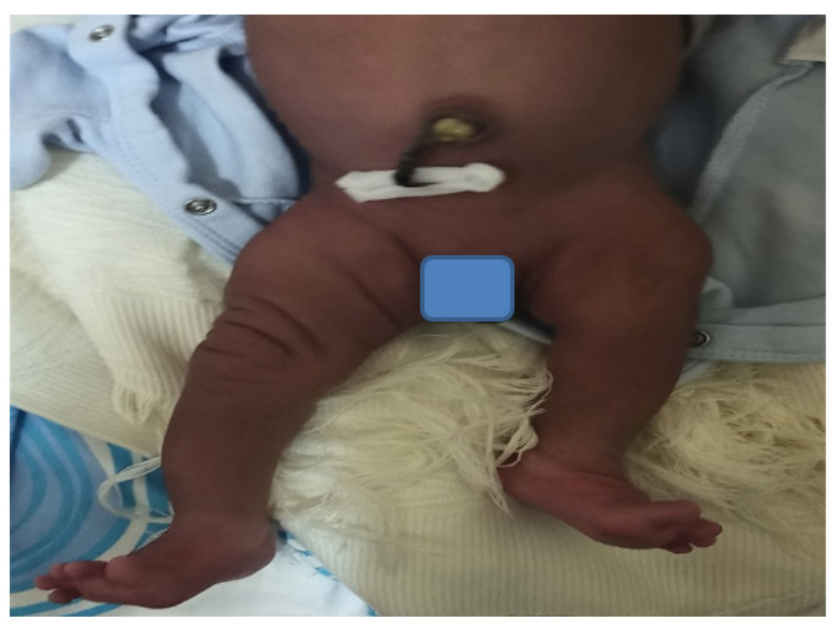

Figure 2A: Clinical picture of index case 2, a 1-day-old male baby with a thick left thigh that is short and bulkier than the right. The left hip joint was abducted, flexed, and laterally rotated.

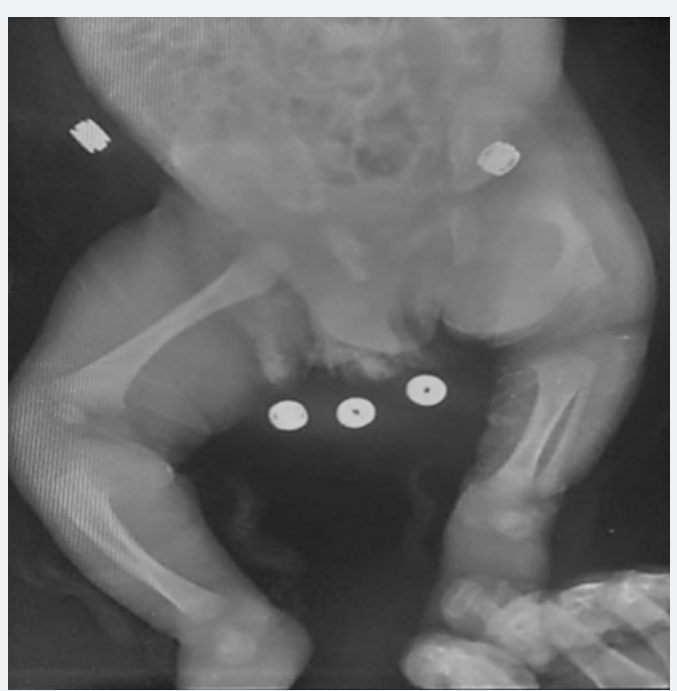

Figure 2B: X-rays of index patient 2 showing a shortened left femur with absence of the femoral head. The acetabulum looked normal. The distal femoral condyles look hypoplastic.

\section{Discussion}

PFFD is a rare disease and has an incidence of 1.1 to 2 in 100,000 live births [4]. The mode of inheritance is sporadic; however, a few familial cases have been reported [11]. Cases of PFFD have been reported in Africa [7-10] but none in Cameroon before now. Having two cases of this sporadic disease within a period of 2 months in our context among which a case of femoral agenesis is our main aim for this report. PFFD is unilateral in 85 to $90 \%$ of reported cases although some authors have reported bilateral cases $[8,12]$. Most cases are diagnosed at birth; however, prenatal diagnosis could be made using ultrasound scans during routine prenatal visits $[11,12,13]$. PFFD has not been proven to be a genetic disease and should be differentiated from other genetic diseases with similar manifestation. These include femoral hypoplasia-unusual facies syndrome also called femoral-facial syndrome, femur/fibula/ulnar hypoplasia syndrome and limb/ pelvis-hypoplasia/aplasia syndrome also called Al-Awadi/RAASRothschild's syndrome [10]. Genetic screening was not done for our two cases because it is not possible in our context due absence of adequate resources. However, both babies each had isolated anomalies in the left thighs with normal facial features, consistent with PFFD. 


\section{Orthopedics and Rheumatology Open Access Journal (OROAJ)}

PFFD commonly presents with limb discrepancy and short flexed, abducted, and externally rotated thigh [14]. Both of our patients presented with unilateral left lower limb shortening with flexed, abducted, and externally rotated thighs. These signs were more striking in case 1 who had femoral agenesis. PFFD presenting as isolated absence of the femur is very rare and is among the most severe forms of the disease [14]. A few babies with PFFD including our index patient 2 had a breech presentation at delivery (either normal or cesarean delivery). However, breech presentation has not been found to be a risk factor for PFFD [15,16]. Several classification systems described congenital anomalies of the femur based on radiological findings. The most used classification is the one described by Aitken and modified by Amstutz $[17,18]$. These classification systems take into consideration the presence of the femoral head, a stable hip joint, or acetabular hypoplasia. They described four classes ranging from class A which is the less severe form to class $\mathrm{D}$ which is the most severe form (Table 1 ). According to the Aitken's classification, our index patient 2 was class B while our index patient 1 could not be classified using this system.

Table 1: Aitken's classification.

\begin{tabular}{|c|c|c|}
\hline Class & Femoral head & Acetabulum \\
\hline A & Present with varus deformity & Normal \\
\hline B & Present with delayed ossification, varus deformity & Mild dyplasia \\
\hline C & Absent & Severe dysplasia \\
\hline D & absent & Absent \\
\hline
\end{tabular}

Paley later published a classification that is more focused on pathologic factors determining management strategies $[10,19,20]$. The Paley's system is described as follows (see figure 3):

$>$ Type 1 - intact femur with mobile hip and knee

- $1 \mathrm{~A}-$ normal ossification of the femur

- $1 \mathrm{~B}-$ delayed ossification

$>\quad$ Type 2 - mobile pseudarthrosis (false joint)
- $\quad 2 \mathrm{~A}-$ femoral head present

- $\quad 2 B-$ femoral head missing or fused to the hip

$>\quad$ Type 3-major deficiency of the femur

- $3 \mathrm{~A}-$ knee motion greater than $45^{\circ}$

- $\quad 3 \mathrm{~B}-$ knee motion less than $45^{\circ}$

- $\quad 3 \mathrm{C}-$ femur absent

$>\quad$ Type 4 - deficiency at the knee joint

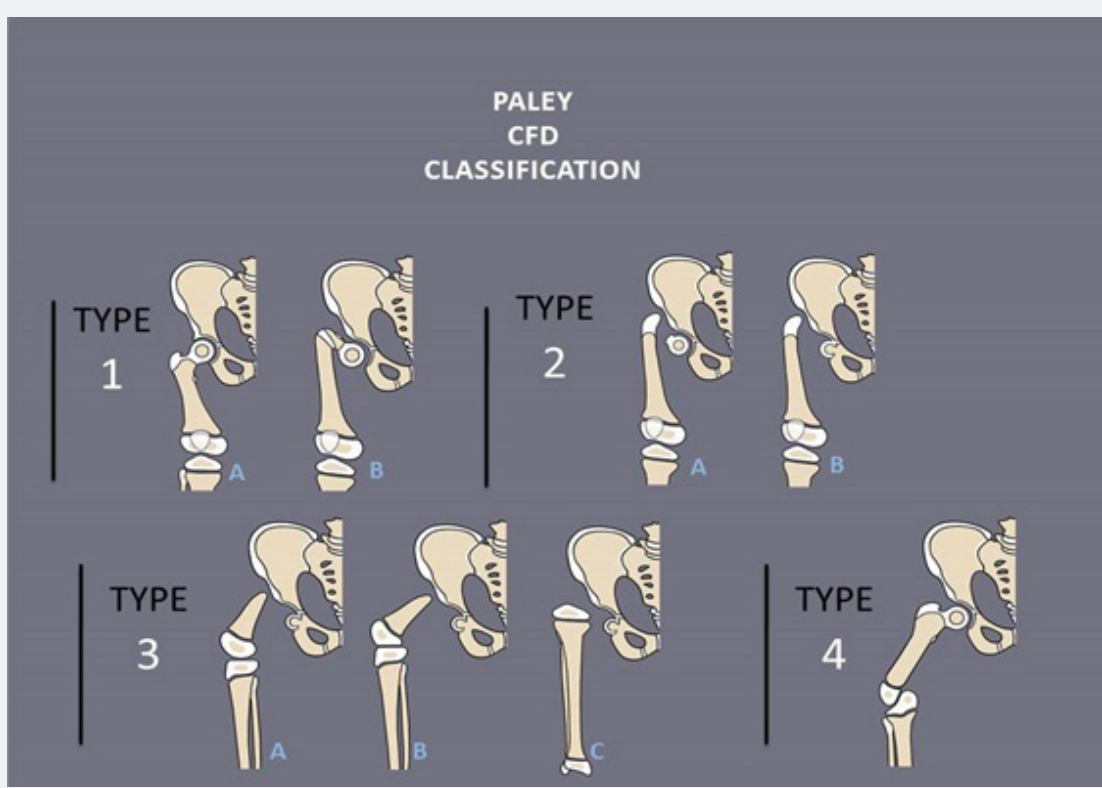

Figure 3: A picture illustration of the Paley's classification of PFFD. Source: The Paley Foundation2015. https://paleyinstitute.org

This therefore means that our index patient 1 is Paley class 3C, while patient 2 is Paley class 3B.
Many risk factors for PFFD have been reported including as hypoxia, ischemia, diabetes mellitus, irradiation, chemical toxins, microbiological agents, and hormones. Other risk factors included 
mechanical injuries, thermal injuries, thalidomide exposure, and fetal trauma between the 4thand 8th weeks of gestation $[6,7,10]$. However, none of these factors were present in our indexed patients or their mothers. Treatment of PFFD is very challenging, complex and requires joint efforts from prosthetists, pediatric orthopedic surgeons, and physical therapists $[8,21]$. Treatment aims at the establishment of the hip stability, lengthening of the affected lower limb, and accomplishment of the normal anatomic alignments [18-21]. If left untreated, PFFD could result in severe functional impairment, severe psychological damage, and scoliotic deformity of the spine causing chronic back pain [12]. The treatment modalities of PFFD depend on its severity $[8,17,18,19]$. For limb discrepancy less than $20 \mathrm{~cm}$, nonsurgical management is an option, however, if the discrepancy is greater than $20 \mathrm{~cm}$ with severe dysplasia, knee arthrodesis and foot amputation for prosthesis application is an optional choice of treatment [14]. In developed countries, authors have reported a good long-term prognosis after surgical correction of PFFD [22]. Conservative management has been the main treatment modality in the cases described in Africa due to either non-availability of limb lengthening facilities, or the cultural denial to amputation [7-10]. The parents of our index patients have been counselled to adhere to referral to a more specialized center, or accept subsequent regular visits at the clinic, with the possibility of limb lengthening soon and/or subsequent amputation and prosthetic replacement.

\section{Conclusion}

PFFD is a rare congenital anomaly with varying clinical presentation. The most severe form is femoral agenesis which is much rarer in the literature. The diagnosis of two cases of a sporadic disease like PFFD in Cameroon, one of which is femoral agenesis calls for documentation. Definitive treatment of this anomaly is complex, challenging, multidisciplinary, and somewhat difficult to carryout in limited resource facilities.

\section{Data availability}

Data is available and cannot be released due to compliance with patient privacy.

\section{Conflicts of Interest}

No authors have conflicts of interest to declare.

\section{Source of funding}

None.

\section{References}

1. Krakow D, Rimoin DL (2010) The skeletal dysplasias. Genet Med 12(6): 327-341.

2. Pandey D, Pai M, Nambiar J, Lewis L, Pandey V (2008) Gollop-Wolfgang complex - a rare limb deficiency syndrome: case report and review of literature. Internet J Gynecol Obstet 9: 1.
3. Day HJB (1991) The ISO/ISPO classification of congenital limb deficiency. Prosthet Orthot Int 15: 67-69.

4. Gerscovich EO, Sekhon S, Loehfelm TW, Greenspan A (2017) Fetal ultrasound: early diagnosis and natural evolution of proximal femoral focal deficiency. J Ultrason 17(71): 294-298.

5. Ifesanya AO, Omololu BA (2012) Proximal focal femoral deficiency in Ibadan a developing country's perspective and a review of literature. Niger J Paed 39(2): 75-78.

6. Filly AL, Robnett-Filly B (2004) Syndromes with focal femoral deficiency; strengths and weaknesses of prenatal sonography. J Ultrasound Med 23(11): 1511-1516.

7. Felix U Uduma, Edwin M Dim, Ngozi R Njeze (2020) Proximal femoral focal deficiency - a rare congenital entity: two case reports and a review of the literature. Journal of Medical Case Reports 14(1): 27.

8. Ifesanya AO, Omololu BA (2012) Proximal focal femoral deficiency in Ibadan a developing country's perspective and a review of the literature. Niger J Paed 39(2): 75-78.

9. Kubwimana O, J Gashegu, A Uwineza (2019) Proximal femoral focal deficiency associated with fibular hemimelia: an uncommon experience, case report and review of literature. Rwanda Medical Journal 76(1).

10. Manal M Thomas, Angie M S Tosson, Mohamed B Taher (2020) Unilateral Isolated Proximal Femoral Focal Deficiency in an Egyptian Infant and Review of Literature. Journal of Child Science 10(1): e126-e133.

11. Mailath-Pokorny M, Timor-Tritsch IE, Monteagudo A, Mittal K, Konno F, et al. (2011) Prenatal diagnosis of unilateral proximal femoral focal deficiency at 19weeks' gestation: case report and review of the literature. Ultrasound Obstet Gynecol 38(05): 594-597.

12. Doger E, Kopuk SY, Cakıroglu Y, Cakır O, Yucesoy G (2013) Unilateral isolated proximal femoral focal deficiency. Case Rep Obstet Gynecol 2013: 637904.

13. Makvandi S, Kolahkaj M (2019) A Case of Neonatal Birth with Congenital Bilateral Femoral Deficiency Undetected in Prenatal Ultrasound. Journal of Midwifery and Reproductive Health 7(2): 17121715.

14. Bedoya MA, Chauvin NA, Jaramillo D, Davidson R, Horn BD, et al. (2015) Common patterns of congenital lower extremity shortening: diagnosis, classification, and follow-up. Radiographics 35(04): 1191-1207.

15. Babay Z (2004) Proximal femoral focal deficiency in a newborn. Ann Saudi Med 24(6): 482-483.

16. Lin TH, Chung CH, Shih JC, Lin CH, Lee CN, et al. (2013) Prenatal diagnosis of proximal femoral focal deficiency: a case report and literature review. Taiwan J Obstet Gynecol 52(2): 267-269.

17. Aitken GT (1969) Proximal femoral focal deficiency: definition, classification and management. In: Aitken GT. Ed. Proximal Femoral Focal Deficiency: a congenital anomaly. National Academy of Sciences, Washington DC, USA.

18. H C Amstutz (1969) The morphology, natural history and treatment of proximal femoral deficiency," in Proximal Femoral Focal Deficiency: A Congenital Anomaly, G T Aitken, Ed., p. 50, National Academy of Sciences, Washington, DC, USA.

19. Paley D (1998) Lengthening reconstruction surgery for congenital femoral deficiency. In: Herring JA, Birch JG, eds. The Child with a Limb Deficiency. Rosemont: American Academy of Orthopaedic Surgeons, pp. 113-132.

20. D Paley (2016) Surgical reconstruction for fibular hemimelia," Journal of Children's Orthopaedics, vol. 10(6): 557-583. 
21. Gupta SK, Alassaf N, Harrop AR, Kiefer GN (2012) Principles of rotationplasty. J Am Acad Orthop Surg 20(10): 657-667.

22. Westberry DE, Davids JR (2009) Proximal focal femoral deficiency
(PFFD): management options and controversies. Hip Int 19(Suppl 6): S18-S25.

Your next submission with Juniper Publishers will reach you the below assets

- Quality Editorial service

- Swift Peer Review

- Reprints availability

- E-prints Service

- Manuscript Podcast for convenient understanding

- Global attainment for your research

- Manuscript accessibility in different formats ( Pdf, E-pub, Full Text, Audio)

- Unceasing customer service

Track the below URL for one-step submission https://juniperpublishers.com/online-submission.php 